\title{
The application of traditional Chinese cultural elements in modern graphic design
}

\author{
Yunling LIU \\ Art Institute \\ Jiujiang University \\ Jiujiang, China
}

\begin{abstract}
In today's world of cultural exchange on the stage, how will Chinese elements with modern graphic design combine to better showcase our unique traditional culture and national identity, has become an important issue faced by graphic designers. From the three constituent elements of traditional Chinese culture in Chinese calligraphy, traditional auspicious patterns, the national colors, elaborate Chinese traditional elements in modern graphic design applications, and explore how to absorb the traditional cultural elements, used in modern graphic design, forming Nationalization has a distinctive, modern Chinese-style design.
\end{abstract}

Keywords- traditional culture; artistic elements; Graphic Design

\section{INTRODUCTION}

In today's world, "is also the nations of the world's" design trend gradually develop open, and China has its unique cultural background and the rapid development of the economic situation active on the world stage, the world recognized the potential of China's economic development and culture the idea to bring the impact in the international arena, "Made in China", "China design" common practice. Chinese modern graphic design real rise in the beginning of the 1980s, along with the establishment and improvement of art and design disciplines. In ten years time across developed economies for decades after the design development stage, and when we go in-depth analysis of design work, they noticed that our work is the lack of culture, the lack of a national characteristic, which also it is the root of our graphic design lies behind. With the continuous development of society, more and more people of insight to realize the importance of Chinese traditional culture of modern design, there are a growing number of designers in the appeal to the essence of traditional culture into modern design works go. However, our graphic design work, he also discovered another phenomenon; many works more indiscriminately copy the traditional elements, so that you can reflect ethnic and cultural. Therefore, the traditional elements of traditional culture and modern graphic design intervention also requires a process, because many of the traditional elements of our images and patterns do not necessarily need to meet the aesthetic needs and development of the modern era, which requires us to have an understanding, absorption, and then the creative process, so that it can better integrate into the modern graphic design works, so that it can truly reflect national characteristics and cultural connotations. With the true design language of localization and nationalization and the theoretical system design language, and by virtue of the Chinese profound culture charm, the graphic design of China will tower above the other designs and become a pioneer in the trend.

\section{THE USE OF TRADITIONAL CALLIGRAPHY IN MODERN GRAPHIC DESIGN ELEMENTS}

China is a traditional ancient civilizations, has a long history, which has voluminous shapes form and aesthetic form. A broad range of Chinese culture breeds Chinese designers, excellent traditional culture but also to provide a rich source of creativity. Graphic design works mainly graphics, color and text as the main visual elements. Text in the graphic design work is not just convey information, but also plays the role of culture heritage and even landscaping. So we will work in the text put forward higher requirements. Most graphic design works are generally willing to use the word computer art, because it is convenient, fast, standardized; but the quintessence of Chinese culture compared to the traditional art of calligraphy, it appears dull, lack of spirit and vitality, the most important is the lack of artistry. All the designers are aware - Innovation is the soul of design. "Tang Dynasty calligrapher Li Yong has a maxim: 'I learned to die, like me were vulgar.' Expresses the idea of calligraphy requires constant innovation and inventiveness in fact not only calligraphy, all kinds of art are popular faces in its development process. The new style, 'Don Juan' is its nature. "The graphic design requires that we must be better to explore the graphic elements, color elements and text elements, to innovate. Emphasizes the aesthetic charm of Chinese art, mood, and the pursuit of modern design is also charm and mood. Chinese traditional calligraphy elements form, potential, meaning the clever use of, no doubt designed to provide a wider sway space for graphic design work. Designers can work according to the needs of the viewer as well as their perception of the psychological, to better express some emotion, conveys information, while the cultural connotation of the design work has also been some improvement. In graphic design works, to be flexible in the use of traditional calligraphy elements, so that works more with a flavor of the times, and then play a finishing touch. When using traditional calligraphy elements must be coordinated with the entire work, as opposed integration. We can use the computer for proper calligraphy design elements to enhance the design of personalized calligraphy, traditional calligraphy elements giving new ideas to make graphic design works have a stronger visual shocking. Graphic 
design graphic works can draw nourishment from traditional calligraphy element. We can break up the combination of the way to show the graphic text meaning, different from the usual text to enhance the visual impact. You can also aid means calligraphy pen and ink to create new graphics. Many excellent designers in this way is through the traditional Chinese calligraphy design elements into their work among the design in order to enrich their expression to express feelings, reflecting the national spirit. Traditional calligraphy element here is beyond its original meaning, has become a kind of Chinese culture worldwide design language. It is because of this design reflects the Chinese culture and characteristics of Chinese culture reflects the insights and experience, it will get people's favorite. Chinese culture is profound, any kind of culture long enough for us to taste. Future designs will inevitably tend to human design, the user-friendly design; the Chinese traditional culture is bound to its far-reaching impact. Chinese calligraphy is an ancient art, it is accompanied by the development of Chinese civilization and development, and it is a unique aesthetic object of the Chinese nation. Beauty, physical beauty of Chinese calligraphy melody and mood of the United States have been increasingly used by modern designers, and modern design gives a unique national style and characteristics of the times.

\section{TRADITIONAL AUSPICIOUS PATTERNS IN MODERN GRAPHIC DESIGN}

In fact, no matter how colorful the modern life is, the beautiful brilliant traditional culture is always the treasure of wisdom to our designers. In modern graphic design graphic re-creation of traditional, modern graphic design can enrich the visual vocabulary. "2l century will be an era of ideologies and cultures clash. A culture will not eat another culture; a way of life does not replace another way of life, but the mutual complementarities and common development, the formation of multicultural coexistence situation. "in the background of globalization, ongoing between traditional culture and modern culture, Eastern culture and Western culture collide and exchange, new ideas, new technologies, new thoughts came into being, the development of the graphic arts space also will be expanded. Early graphics gradually positioning information of modern society gives a new visual meaning in modern graphic design, through to the modern visual elements associated with the re-conversion, the development to create a new graphic art visual grammar structure. And this again is associated with the conversion, neither the surface in the form of traditional graphic arts organization completely abandoned, nor is the traditional graphic arts organizations complete "copy", but in the cultural context of modern society, learning the essence of traditional culture Based on the re-interpretation of the traditional visual graphic symbols. Is highly refined graphical symbols from the traditional style, meaning, charm, etc., ingenious combinations and connotation extends to its full integration into the modern aesthetic of visual patterns. The traditional Chinese auspicious symbol "Dragon and Phoenix", "Gods hi", "year after year there are fish", "Good Fortune" and so very local Chinese taste, through symbolism, metaphor, pun, homophonic and other techniques to deliver the nation emotional and wonderful attitude to life, their way of thinking and conceptualization wonderful idea graphic vocabulary enriched the world culture, has become a graphic design interpretation of local culture often choose visual language. In recent years, China's graphic designer in his works continues to explore innovative auspicious culture, thereby seeking an entry point for Eastern and Western cultures. For example, Mr. Kan Tai-Keung in design, "Kan Tai-Keung Design Co., Ltd.," the company logo on the process of injecting the auspicious Chinese culture reflect the "one mind, connected to each other" and "side wins" pattern, while in the shape of conduct a new visual interpretation, meaning the company philosophy mutual trust and sincere way relationship. Chinese people since ancient times, the pursuit of good luck and happy life, and Chinese traditional auspicious patterns are well expressed the good wishes of the people. Chinese traditional drawing a lot of good symbolism of animals, plants and the expression pattern is equally applicable to modern graphic design. These concepts include auspicious "festive smug, Auspicious Hannaford, more children live longer", etc., in addition to a variety of auspicious animals, plants, and "smug", "moir é ", "side wins," and other patterns, as well as species totem symbols. Graphics are widely used in Chinese traditional modern graphic design. Such as: Bank of China and China sign Yulong choose simplicity as the main symbol of the Chinese nation, the level of reverse Yulong, just China (China) in the first letter to symbolism more prominent. In addition, China Unicom signs crafted from Buddhism "Endless knot" shape, placed "a long history, going, complementary," meaning that the flag is filled with ancient oriental lucky charm on the whole; Beijing 2008 Olympics logo is also the use of "Endless knot" shape, while the application of Chinese art unique freehand technique, with strong ethnic style; China mobile and China Post logo flags are using traditional graphics "fret" mode, the graphic elements of the traditional "extended form "constantly break down, change and reconstruction. These outstanding design work, to fully tap the charm of traditional Chinese art graphics, and make evolution, given its distinctive characteristics of the times, while the designer to accurately express the unique ideas and personality, people aftertaste.

\section{CONFUCIANISM ON CHINESE TRADITIONAL AND MODERN GRAPHIC DESIGN GRAPHICS}

First, the influence of Confucianism on Chinese traditional culture is the most far-reaching. Confucianism originated in China in the "Axial Age", namely Chinese Qin Dynasty. Confucius, Mencius, Xun Zi thought the doctrine laid the scope of the study of Confucian ideology, basic proposition, the core idea and basic features. The core of the Confucianism in Qin dynasty concerns about the humanity and human relations. In the pre-Qin Confucianism inheritance and development on the basis of the development of the Han Confucianism has experienced several stages of Neo-Confucianism, Ming and Qing Dynasties, such as NeoConfucianism. At different stages of development, 
Confucian doctrine because of different historical factors, social factors and generates a lot of changes. No matter how the Confucianism develops, "Heaven, people-oriented, energetic and promising, your monk in the basic values of Confucian cultural spirit", is a traditional Chinese spiritual connotation basic graphics.

China is traditional agricultural countries, the ancient ancestors faced with harsh natural conditions, in the process of survival; develop a positive, optimistic character Lotto. "And do farming and food sunrise, sunset, dig wells for water. The power of being an emperor means nothing to me!" This is the formation of Chinese traditional culture on Vigorous pursuit. A gentleman should be always selfreliance with endless." Vigorous embodies the Chinese people a positive attitude towards life, emphasizing the man has to be in line with moral principles, as well as the pursuit of Chiang Kai-shek outspoken character. "Wealth can not be obscene, and rank can not move, force can bend." Chinese traditional drawing "plum, orchid, bamboo, chrysanthemum" reflects the "vigorous and promising" thought pursuit.

In traditional Chinese culture, such as it is always sad dying unfavorable factors attributed to favorable factors, looking forward to "the situation improves," through some spiritual sustenance and spiritual solace and obtain balance. Chinese traditional graphic expression of this is the spiritual moderation. "Moderation" reaches "peace." And different requirements of the development which means things various factors reconcile unity, unity among the have changed, seek unity in change. Harmonization means the development of things have interlinked factors affected by impact of Chinese traditional graphics reflect the change in the shape of a uniform rule.

\section{CONCLUSIONS}

Today's world is a highly modern, information-based society, followed by a new culture, a new trend tremendous impacts on Chinese traditional culture. Traditional cultural show unique charm, it is modern graphic design need to find the source. This allows us to come to realize that China's contemporary graphic design should be based on national traditions. Faced with the design wave of globalization, every modern graphic designer should play to their strength, so that our modern graphic design art invincible in international competition. The traditional culture and modern design language combined to push towards internationalization; it is our great mission of the new generation of designers given by the history.

\section{References}

[1] Yao Huanyang Influence on modern graphic design of traditional Chinese paper-cut art [J] intelligence, 2014, 29: 280.

[2] Huang Min The design localization studies [J] based on the harmonious coexistence of traditional aesthetic plane South China Normal University (Social Sciences), 2014, 05: 156-160 + $164+165$ +2 .

[3] Yi Zhaoyong Traditional arts and modern design [J] modern economic information, 2014, 18: 451.

[4] Guo Xinxin Aesthetic Significance of Chinese Characters Art in Graphic Design [J] Northwest Art, 2014,04: 126-127.

[5] Gu Huimin Affect the traditional Chinese color concept of modern graphic design applications [J] Art Education Research, 2014, 16: 89.

[6] Meng Xiangyu Fusion of traditional and modern design concepts auspicious patterns of [J] electronic production, 2014, 13: 238-239. 